
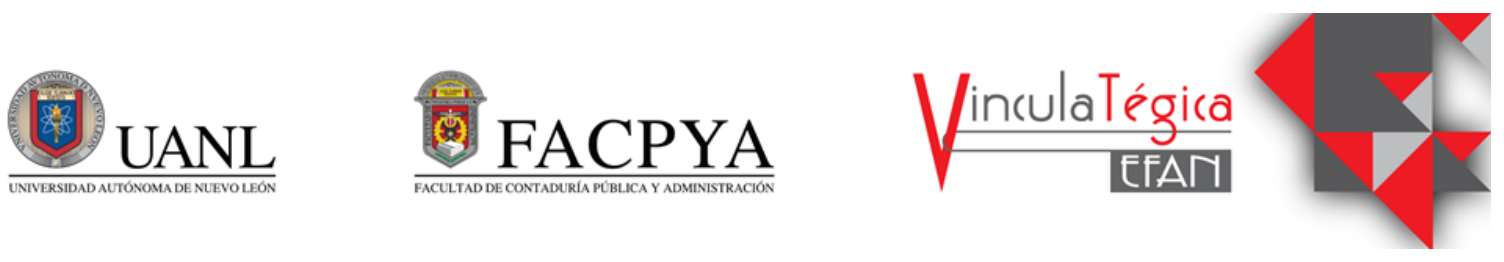

\title{
Un mapa de las nuevas economías
}

\author{
David Ceballos Hornero ${ }^{1}$ \\ ${ }^{1}$ Universitat de Barcelona, ceballos@ub.edu, Av. Diagonal 690, 08034, Barcelona. Departamento de \\ Matemática Económica, Financiera y Actuarial. Universitat de Barcelona
}

Información del artículo revisado por pares

Fecha de aceptación: junio-2021

Fecha de publicación en línea: octubre-2021

DOI: https://doi.org/10.29105/vtga7.2-76

\section{Resumen}

La crítica y limitaciones en la explicación sobre todo de las crisis económicas de las últimas décadas ha fomentado la aparición de nuevos enfoques económicos, algunos con una visión práctica para adaptarse la visión ortodoxa dominante y otros con una más teórica que proponen cambios abruptos en la creación de riqueza, que muchas veces acaban solapándose o pueden provocar una confusión de conceptos porque los diferentes enfoques pueden tener bases comunes pero los conceptos en los que se basan pueden ser muy distintos. En el presente artículo se analizan más de 30 de estos enfoques alternativos clasificándolos respecto a cuatro ejes (económico, sostenible, social y responsable), según sean sus impactos en las dinámicas económicas (valor dinero), en la sostenibilidad medioambiental (posibilidades generaciones futuras), en la justicia y derechos sociales (efectos sobre desfavorecidos), y en la responsabilidad moral (consideración reparación del daño revirtiéndolo). El resultado es un mapa de los diferentes enfoques económicos que muestra, en general, los enfoques que priorizan la dimensión económica sobre todo son bajos en sostenibilidad y consideraciones sociales, los sostenibles se mueven en casi todo el espectro del mapa, los sociales tienden a olvidar la dimensión medioambiental, mientras que los responsables tienden a estar cerca del centro. Este mapa ayuda a entender o clasificar mejor las políticas o gestión pública de las diferentes economías en tanto que están basadas, justificadas o aprovechan la narrativa discursiva del enfoque económico o sus conceptos clave que toman como referencia.
Abstract
Limitations in the explanation of orthodox economic theory, especially from the economic crises of the last decades, is one of the causes for the emergence of new economic approaches, some with a practical vision adaptable to the dominant orthodox vision and others with a more theoretical point of view with proposal of abrupt changes in wealth considerations. These new approaches suppose often overlapping and confusions between concept because the approaches are related but the concept that they use not. In this article, we analyse more than 30 of these alternative approaches, classifying them according to four axes (economic, sustainable, social and responsible), according to their impacts on economic dynamics (money value), on environmental sustainability (possibilities for future generations), on justice and social rights (effects on the disadvantaged agent), and moral responsibility (consideration of repairing the damage by reversing it). The result is a map of the different economic approaches that shows the economic dimension reduces the sustainable and social considerations, the sustainable approaches move in almost the entire spectrum on the map, social approaches tend to forget the environmental dimension, while those responsible approaches tend to be close to the centre. This map helps to understand or classify in a more accurate way the policies or public management of the different economies, because every political decision about Economy is based, justified or associated to an economic approach or its key concepts.

Key words: Economic Approaches, Sustainability, Social, Responsibility 
Palabras clave: Enfoques económicos, sostenibilidad, social, responsabilidad.

\section{INTRODUCCIÓN}

La crisis socioeconómica que la larga pandemia sanitaria provocada por el contagio global por la covid19 refleja diferentes prioridades en el enfoque de los planes de recuperación económica de los principales bloques económicos. Así, la Unión Europea apuesta por reforzar su pacto verde europeo (green deal) en el sentido de apoyar sobre todo propuestas de recuperación y transformación económica que mejoren el impacto sobre el medio ambiente. Mientras, por el contrario, el plan de recuperación de Estados Unidos en la nueva época Biden se caracteriza más por visualizar la respuesta social. Esta dualidad entre el énfasis de lo ambiental y de lo social está muy presente en los diferentes enfoques y teorías económicas existentes que acaban siendo el fundamento o la justificación de las diferentes políticas públicas.

De hecho, se ha consolidado en la gestión privada que la nueva gestión pública se acaba reflejando, una visión para que los factores medioambientales, sociales y de gobernanza (ESG por las siglas en inglés), que reflejan las tres dimensiones, aparte de la económica, que marcan los diferentes enfoques económicos: sostenibilidad, sociedad y responsabilidad.

El núcleo y explicación de la economía moderna ha ido evolucionando (Naredo, 1987) desde la escuela clásica y su visión mercantil basada en los vicios privados (Mandeville), el egoísmo individual y la mano invisible del mercado (Smith), las ventajas competitivas (Ricardo) o la riqueza como virtud (Malthus), y las primeras ideas de los fisiócratas (siglo XVIII) que ponían el énfasis en el crecimiento generado por la producción y el consumo con una visión organicista de las riquezas generadas por la Madre-Tierra (plantas, animales y minerales). De ahí el núcleo evolucionó hacia el valor y la utilidad en la escuela neoclásica en un contexto de recursos limitados (o escasos) o no reproducibles y la búsqueda y contabilización
JEL Codes: A10, B50, Q50

del valor añadido, y, por tanto, de la cuantificación monetaria y la aparición del capital como factor productivo. Comienza así un "divorcio", en palabras de Naredo (2004), entre la economía y la ecología al separarse del mundo físico la primera y entrarse en lo apropiable con valor de cambio, por lo que impactos no monetarios ni individualizables quedaban ignorados.

Se va consolidando así una visión más matemática de la economía que busca el equilibrio y con el desarrollo de la teoría de la decisión la delimitación de ciertas reglas que aseguraran su existencia y unicidad como la racionalidad (búsqueda del máximo beneficio individual), la representación de la incertidumbre desde la teoría de la probabilidad y el valor esperado con funciones de utilidad convexas, etc. Así, la Teoría económica ortodoxa se acaba basando en la defensa de la eficiencia y competencia del mercado (asignación óptima de recursos de acuerdo a la confluencia de intereses individuales) y la racionalidad (la preferencia por la mayor cantidad), derivando en unos modelos económicos basados en la priorización de las alternativas de mayor beneficio esperado y en la actuación por el interés propio (egoísta o corporativa).

La visión matemática de la economía llega a su auge en el siglo XX con la representación gráfica de la Macroeconomía (modelo IS-LM de oferta y demanda) y el desarrollo de la Econometría (el progreso de la teoría económica en sus relaciones con la estadística y las matemáticas).

El enfoque matemático y utilitarista acaba promoviendo una actividad económica guiada por el beneficio privado y la acumulación de desequilibrios generados por la actividad humana de impacto y preocupación global. Impactos tanto sociales y medioambientales, recogidos sobretodo en el presente siglo con los Desafíos del Milenio (2000) y la Agenda 2030 con los Objetivos de Desarrollo Sostenible (2015) de la ONU.

Este contexto ha sido la base para la aparición de diferentes visiones y discursos 
económicos críticos y heterodoxos para un enfoque más holístico o para superar diferentes críticas o insuficiencias de la Teoría económica ortodoxa. Toda una serie de nuevos enfoques que muchas veces se complementan, relacionan o sustituyen entre sí, llegando a generar cierta confusión y pérdida de una terminología común.

Confusión que afecta también a una correcta interpretación de las decisiones y políticas públicas económicas porque las mismas se basan, justifican o aprovechan las ideas o conceptos clave de un enfoque económico de referencia.

En el presente artículo se repasan las características de los principales enfoques económicos aparecidos en las últimas décadas como críticos con la teoría económica dominante u ortodoxa y su visión matemática y utilitarista. Para el análisis de sus relaciones se plantea un análisis de los diferentes enfoques según tres dimensiones o en tres ejes: sostenibilidad, sociedad, responsabilidad.

Así, en el presente artículo se analizan, sin voluntad de ser totalmente exhaustivos, hasta 32 enfoques económicos, incluido el ortodoxo, en las dimensiones mencionadas para proyectar un mapa según la situación de los mismos, distinguiendo los diferentes enfoques según la importancia de cada dimensión en su génesis. En el marco teórico se explica las clasificaciones que se plantean para agrupar los enfoques económicos y en el método se describe cada enfoque económico, para acabar con el mapa en el apartado de resultados.

\section{MARCO TEÓRICO}

Las crisis económicas, sobre todo desde los años 70 del siglo $\mathrm{XX}$, han sido causa de falsación de la Teoría económica dominante u ortodoxa porque explicaba de forma insuficiente o no había permitido la detección o una respuesta satisfactoria a la crisis. Este contexto ha sido la base para la aparición de diferentes visiones y discursos económicos críticos y heterodoxos para un enfoque más holístico. Nuevos enfoques que los diferentes gestores públicos y Economías también han asumido a la hora de decidir o justificar sus políticas económicas.

\subsection{Dimensiones de análisis}

Los nuevos enfoques han ido apareciendo sobre todo por la incorporación de restricciones o de nuevas dimensiones en el funcionamiento del sistema económico, sobre todo en temas relacionados con el medioambiente, los derechos sociales y la responsabilidad moral ante el daño. Así, se plantean tres dimensiones de análisis: sostenibilidad, sociedad y responsabilidad.

Por sostenibilidad, desde el punto de vista económico, se puede entender como la satisfacción de las necesidades actuales sin comprometer la capacidad de las generaciones futuras de satisfacer las suyas, lo que implica principalmente una garantía de la capacidad biológica del planeta y el cuidado del medio ambiente, entre otros. Un concepto que en la terminología más extendida se suele asociar también a una actuación responsable, en el sentido de respetuoso con el medioambiente.

Por Sociedad, en el sentido de justicia social, se hace referencia a la priorización de los derechos y bienestar social por parte del enfoque económico analizado en el sentido de los derechos que facilitan a las personas desarrollarse en autonomía, igualdad y libertad, así como el acceso a un bienestar y condiciones económicas para una vida digna.

Finalmente, la Responsabilidad se plantea como una consideración moral de revertir los efectos y consecuencias, directos e indirectos y a corto y largo plazo, de la decisión económica.

\subsection{Los enfoques económicos}

En este artículo se analizan hasta 32 enfoques económicos, comenzando por la Teoría económica dominante (la ortodoxa) y las ideas críticas que han ido surgiendo, sobre todo después de cada gran crisis o desastre social, ambiental o económica, que en general intentan sustituir la Economía ortodoxa tradicional por otros enfoques que acerquen temas como la salud planetaria, la mejora de los derechos sociales y la ética de las 
decisiones.

\section{MÉTODO}

Se parte del análisis de cada uno de los 32 enfoques económicos considerados para la cuantificación del impacto en las dimensiones consideradas. Se trabaja con una escala cualitativa de cinco niveles (muy bajo, bajo, medio, alto y muy alto).

\subsection{Enfoques de prioridad económica}

Enfoques económicos donde la dimensión económica explica por sí sola el funcionamiento del sistema:

1) Economía ortodoxa o teoría económica dominante (Eor)

Tabla 1 Economía ortodoxa

\begin{tabular}{|c|c|c|}
\hline Núcleo & Valor & Equilibrio \\
\hline $\begin{array}{l}\text { Mercado } \\
\text { como } \\
\text { mecanismo } \\
\text { eficiente y } \\
\text { de } \\
\text { regulación: } \\
\text { oferta- } \\
\text { demanda } \\
\text { (precios, } \\
\text { cantidad) }\end{array}$ & $\begin{array}{l}\text { Utilidad- } \\
\text { competen } \\
\text { cia } \\
\text { Consumo- } \\
\text { producció } \\
\text { n }\end{array}$ & $\begin{array}{l}\text { Largo plazo } \\
\text { estado } \\
\text { estacionario } \\
\text {, salvo } \\
\text { tecnología / } \\
\text { innovación } \\
\text { (dinámica } \\
\text { empresarial) }\end{array}$ \\
\hline
\end{tabular}

\begin{tabular}{|c|c|c|}
\hline $\begin{array}{l}\text { Sostenibilid } \\
\text { ad }\end{array}$ & Sociedad & $\begin{array}{l}\text { Responsabi } \\
\text { lidad }\end{array}$ \\
\hline Muy Bajo & Muy bajo & Bajo \\
\hline $\begin{array}{l}\text { Sólo cuando } \\
\text { los efectos } \\
\text { son } \\
\text { importantes }\end{array}$ & $\begin{array}{l}\text { Prioridad } \\
\text { incentivos } \\
\text { individual } \\
\text { es }\end{array}$ & $\begin{array}{l}\text { Sólo si } \\
\text { distorsionan } \\
\text { el mercado }\end{array}$ \\
\hline
\end{tabular}

Fuente: elaboración propia

2) Economía neokeynesiana (Ene)

Tabla 2 Economía neokeynesiana

\begin{tabular}{lll}
\hline \multicolumn{1}{c}{ Núcleo } & \multicolumn{1}{c}{ Valor } & \multicolumn{1}{c}{$\begin{array}{c}\text { Equilibri } \\
\text { o }\end{array}$} \\
\hline Mercado- & Utilidad- & Equilibrio \\
Estado & competencia & general \\
como & Consumo- & economía \\
mecanismo & producción- & real y \\
eficiente y & ocupación & nominal \\
de & &
\end{tabular}

regulación:

precios y

ocupación

\begin{tabular}{lll}
\hline $\begin{array}{l}\text { Sostenibilid } \\
\text { ad }\end{array}$ & Sociedad & $\begin{array}{l}\text { Responsa } \\
\text { bilidad }\end{array}$ \\
\hline Muy bajo & Bajo & Bajo \\
Sólo & Papel & $\begin{array}{l}\text { Equilibrio } \\
\text { general }\end{array}$ \\
enfoque & Estado & \\
\hline Fuente: elaboración propia &
\end{tabular}

3) Economía digital (Edi)

Tabla 3 Economía digital

\begin{tabular}{|c|c|c|}
\hline Núcleo & Valor & Equilibrio \\
\hline $\begin{array}{l}\text { Mercado } \\
\text { como } \\
\text { mecanismo } \\
\text { eficiente y } \\
\text { de } \\
\text { regulación: } \\
\text { oferta- } \\
\text { demanda } \\
\text { (precios, } \\
\text { cantidad) }\end{array}$ & $\begin{array}{l}\text { Utilidad- } \\
\text { competenc } \\
\text { ia } \\
\text { Consumo- } \\
\text { producció } \\
\text { n digital }\end{array}$ & $\begin{array}{l}\text { Máximo } \\
\text { desarrollo } \\
\text { tecnología y } \\
\text { digitalización }\end{array}$ \\
\hline $\begin{array}{l}\text { Sostenibilid } \\
\text { ad }\end{array}$ & Sociedad & $\begin{array}{l}\text { Responsabilid } \\
\text { ad }\end{array}$ \\
\hline $\begin{array}{l}\text { Bajo } \\
\text { Sin mucho } \\
\text { impacto }\end{array}$ & $\begin{array}{l}\text { Bajo } \\
\text { Prioridad } \\
\text { derechos } \\
\text { digitales }\end{array}$ & $\begin{array}{l}\text { Muy bajo } \\
\text { Dilución } \\
\text { responsabilidad } \\
\text { por anonimato } \\
\text { y } \\
\text { automatización }\end{array}$ \\
\hline
\end{tabular}

4) Nueva Economía Institucional

La economía institucional (Ein) se desarrolla en dos versiones. La clásica (Ein1) que tiene un origen sociológico a inicios del siglo XX y un enfoque teórico en la incorporación de un tercer agente (instituciones) en los grandes agentes económicos (Estado - Mercado), y la nueva economía institucional (Ein2), que se popularizó en el último cuarto del siglo XX y con un enfoque práctico.

Tabla 4 Nueva Economía institucional

\begin{tabular}{lll}
\hline \multicolumn{1}{c}{ Núcleo } & \multicolumn{1}{c}{ Valor } & \multicolumn{1}{c}{ Equilibrio } \\
\hline Mercado- & Utilidad- & Largo plazo \\
Estado- & competenci & estado \\
Estructuras & a & estacionario,
\end{tabular}




\begin{tabular}{|c|c|c|}
\hline $\begin{array}{l}\text { de } \\
\text { relaciones } \\
\text { como } \\
\text { mecanismo } \\
\text { eficiente y } \\
\text { de } \\
\text { regulación: } \\
\text { supervisión } \\
\text { oferta- } \\
\text { demanda }\end{array}$ & $\begin{array}{l}\text { Consumo- } \\
\text { producción }\end{array}$ & $\begin{array}{l}\text { salvo tecnología } \\
\text { / innovación } \\
\text { (dinámica } \\
\text { empresarial) }\end{array}$ \\
\hline $\begin{array}{l}\text { Sostenibili } \\
\text { dad }\end{array}$ & Sociedad & $\begin{array}{l}\text { Responsabilida } \\
\text { d }\end{array}$ \\
\hline $\begin{array}{l}\text { Bajo } \\
\text { Sin mucho } \\
\text { impacto }\end{array}$ & $\begin{array}{l}\text { Bajo } \\
\text { Énfasis en } \\
\text { la parte } \\
\text { contractual }\end{array}$ & $\begin{array}{l}\text { Alto } \\
\text { Exigencia legal } \\
\text { de los contratos, } \\
\text { organizaciones y } \\
\text { estructuras }\end{array}$ \\
\hline
\end{tabular}

Fuente: elaboración propia

\section{5) Economía postkeynesiana (Epo)}

Tabla 5 Economía postkeynesiana

\begin{tabular}{|c|c|c|}
\hline Núcleo & Valor & Equilibrio \\
\hline $\begin{array}{l}\text { Mercado- } \\
\text { Estado } \\
\text { como } \\
\text { mecanismo } \\
\text { eficiente y } \\
\text { de } \\
\text { regulación: } \\
\text { precios y } \\
\text { ocupación }\end{array}$ & $\begin{array}{l}\text { Utilid } \\
\text { ad- } \\
\text { compe } \\
\text { tencia } \\
\text { Cons } \\
\text { umo- } \\
\text { produ } \\
\text { cción- } \\
\text { ocupa } \\
\text { ción }\end{array}$ & $\begin{array}{l}\text { Trayectoria } \\
\text { desequilibrio, } \\
\text { incertidumbre } \\
\text { dinámica }\end{array}$ \\
\hline $\begin{array}{l}\text { Sostenibilid } \\
\text { ad }\end{array}$ & $\begin{array}{l}\text { Socie } \\
\text { dad }\end{array}$ & Responsabilidad \\
\hline $\begin{array}{l}\text { Bajo } \\
\text { Sólo } \\
\text { enfoque } \\
\text { económico }\end{array}$ & $\begin{array}{l}\text { Medio } \\
\text { Papel } \\
\text { Estad } \\
\text { o }\end{array}$ & $\begin{array}{l}\text { Medio } \\
\text { Desequilibrio largo } \\
\text { plazo }\end{array}$ \\
\hline
\end{tabular}

6) Economía del desarrollo (Eds)

Tabla 6 Economía del desarrollo

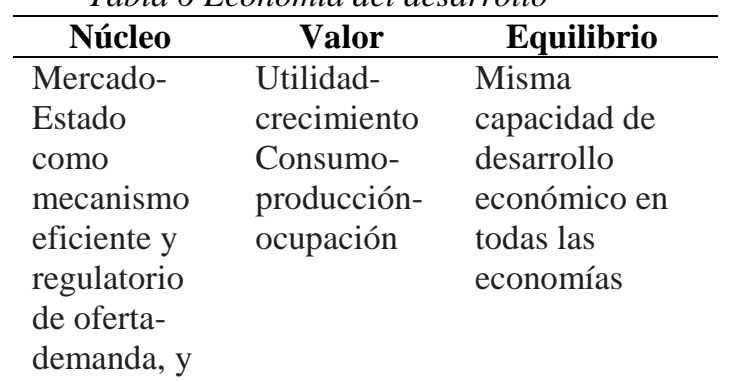

la inversión

\begin{tabular}{|c|c|c|}
\hline $\begin{array}{l}\text { Sostenibilid } \\
\text { ad }\end{array}$ & Sociedad & $\begin{array}{l}\text { Responsabilid } \\
\text { ad }\end{array}$ \\
\hline Bajo & Bajo & Bajo \\
\hline $\begin{array}{l}\text { Sólo } \\
\text { enfoque } \\
\text { económico }\end{array}$ & $\begin{array}{l}\text { Principalme } \\
\text { nte contra } \\
\text { subdesarroll } \\
\text { o, atraso y } \\
\text { desigualdad } \\
\text { entre } \\
\text { colectivos y } \\
\text { zonas }\end{array}$ & $\begin{array}{l}\text { Equilibrio en } \\
\text { el crecimiento } \\
\text { a largo plazo }\end{array}$ \\
\hline
\end{tabular}

\subsection{Enfoques de prioridad medioambiental}

Enfoques económicos donde la dimensión de sostenibilidad se desarrolla a partir de conceptos e ideas biológicos:

7) Economía ambiental (Eam)

Tabla 7 Economía ambiental

\begin{tabular}{|c|c|c|}
\hline Núcleo & Valor & Equilibrio \\
\hline $\begin{array}{l}\text { Mercado- } \\
\text { Estado } \\
\text { como } \\
\text { mecanismo } \\
\text { de } \\
\text { eficiencias } \\
\text { en los } \\
\text { previos que } \\
\text { incluye } \\
\text { externalida } \\
\text { des }\end{array}$ & $\begin{array}{l}\text { Utilidad- } \\
\text { crecimiento } \\
\text { Consumo- } \\
\text { producció } \\
\text { n- } \\
\text { externalida } \\
\text { des }\end{array}$ & $\begin{array}{l}\text { Transición hacia } \\
\text { un equilibrio a } \\
\text { largo plazo que } \\
\text { mantenga } \\
\text { capacidad } \\
\text { reproductiva } \\
\text { natural }\end{array}$ \\
\hline $\begin{array}{l}\text { Sostenibili } \\
\text { dad }\end{array}$ & Sociedad & $\begin{array}{l}\text { Responsabilida } \\
\text { d }\end{array}$ \\
\hline $\begin{array}{l}\text { Medio } \\
\text { Sólo como } \\
\text { externalida } \\
\text { des } \\
\text { comercializ } \\
\text { ables. } \\
\text { Transición } \\
\text { continua a } \\
\text { la } \\
\text { sostenibilid } \\
\text { ad }\end{array}$ & $\begin{array}{l}\text { Bajo } \\
\text { Sólo se } \\
\text { añaden a } \\
\text { externalida } \\
\text { des } \\
\text { compensa } \\
\text { bles }\end{array}$ & $\begin{array}{l}\text { Medio } \\
\text { Transición a } \\
\text { largo plazo }\end{array}$ \\
\hline
\end{tabular}

8) Economía verde (Eve) 
Tabla 8 Economía verde

\begin{tabular}{|c|c|c|}
\hline Núcleo & Valor & Equilibrio \\
\hline $\begin{array}{l}\text { Mercado- } \\
\text { Estado } \\
\text { como } \\
\text { mecanismo } \\
\text { eficiente de } \\
\text { precios e } \\
\text { incentivos } \\
\text { medioambie } \\
\text { ntales }\end{array}$ & $\begin{array}{l}\text { Utilidad- } \\
\text { crecimient } \\
\text { o } \\
\text { Consumo- } \\
\text { producción } \\
\text { responsabl } \\
\text { e con el } \\
\text { medioambi } \\
\text { ente }\end{array}$ & $\begin{array}{l}\text { Búsqueda de la } \\
\text { sostenibilidad } \\
\text { planetaria a } \\
\text { largo plazo }\end{array}$ \\
\hline $\begin{array}{l}\text { Sostenibilid } \\
\text { ad }\end{array}$ & Sociedad & $\begin{array}{l}\text { Responsabilida } \\
\text { d }\end{array}$ \\
\hline $\begin{array}{l}\text { Medio } \\
\text { Se tienen en } \\
\text { cuenta los } \\
\text { riesgos y } \\
\text { amenazas } \\
\text { como } \\
\text { incentivos y } \\
\text { penalizacion } \\
\text { es }\end{array}$ & $\begin{array}{l}\text { Medio } \\
\text { Prioridad } \\
\text { medio } \\
\text { natural }\end{array}$ & $\begin{array}{l}\text { Medio } \\
\text { Políticas activas }\end{array}$ \\
\hline
\end{tabular}

9) Economía azul marina (EAz2)

Hay dos versiones de la Economía azul (Eaz). La primera versión (Eaz1) como alternativa de la Eve a partir de las ideas de Pauli (1994) sobre innovaciones sostenibles de producción ecológica $o$ de sistemas naturales que aprovechan mejor el medio. La segunda versión de la Eaz (Eaz2) es seguramente la más conocida e intuitiva de la importancia de los mares y los océanos como motores de la economía por su gran potencial para la innovación y el crecimiento.

Tabla 9 Economía azul marina

\begin{tabular}{lll}
\hline \multicolumn{1}{c}{ Núcleo } & \multicolumn{1}{c}{ Valor } & \multicolumn{1}{c}{ Equilibrio } \\
\hline Mercado- & Utilidad- & Respecto de los \\
Estado para & crecimient & recursos \\
un uso & o marítimo & marítimos \\
eficiente y & & \\
respetuoso & & \\
mares & &
\end{tabular}

\begin{tabular}{lll}
\hline $\begin{array}{l}\text { Sostenibilid } \\
\text { ad }\end{array}$ & Sociedad & $\begin{array}{l}\text { Responsabilida } \\
\text { d }\end{array}$ \\
\hline Medio & Bajo & Medio \\
Sólo mares & $\begin{array}{l}\text { Prioridad } \\
\text { sostenibili } \\
\text { dad }\end{array}$ & Sólo mares \\
& & \\
&
\end{tabular}

\begin{tabular}{|c|c|c|}
\hline \multicolumn{3}{|c|}{ marítima } \\
\hline \multicolumn{3}{|c|}{ Fuente: elaboración propia } \\
\hline \multicolumn{3}{|c|}{ 10) Bioeconomía (Bec) } \\
\hline \multicolumn{3}{|c|}{ Tabla 10 Bioeconomía } \\
\hline Núcleo & Valor & Equilibrio \\
\hline $\begin{array}{l}\text { Mercado- } \\
\text { Estado } \\
\text { como } \\
\text { mecanismo } \\
\text { de eficiencia } \\
\text { e impulsor } \\
\text { del } \\
\text { crecimiento } \\
\text { económico }\end{array}$ & $\begin{array}{l}\text { Utilidad- } \\
\text { crecimient } \\
\text { o } \\
\text { Consumo- } \\
\text { producción } \\
\text {-ocupación }\end{array}$ & $\begin{array}{l}\text { Estado } \\
\text { estacionario de } \\
\text { control de los } \\
\text { impactos } \\
\text { negativos } \\
\text { medioambientale } \\
\text { s y sociales }\end{array}$ \\
\hline $\begin{array}{l}\text { Sostenibilid } \\
\text { ad }\end{array}$ & Sociedad & $\begin{array}{l}\text { Responsabilida } \\
\text { d }\end{array}$ \\
\hline Alto & Medio & Medio \\
\hline $\begin{array}{l}\text { Se priorizan } \\
\text { las } \\
\text { alternativas } \\
\text { sostenibles } \\
\text { y de menor } \\
\text { impacto }\end{array}$ & $\begin{array}{l}\text { Respuesta } \\
\text { a los retos } \\
\text { sociales }\end{array}$ & $\begin{array}{l}\text { Se sigue } \\
\text { priorizando la } \\
\text { generación } \\
\text { presente y sus } \\
\text { retos, intentando } \\
\text { minimizar el } \\
\text { impacto } \\
\text { negativo futuro }\end{array}$ \\
\hline
\end{tabular}

Fuente: elaboración propia

\section{1) Finanzas éticas responsables (Fet1)}

Se pueden extrapolar dos versiones de las Finanzas éticas. L primera Fet 1 como finanzas responsables y solidarias de vincular los beneficios económicos están intrínsecamente ligados a los beneficios sociales y ambientales. Y la segunda versión, con la misma raíz que las Fet1, pero más crítica y de cambio del funcionamiento habitual del sistema financiero, eliminando la búsqueda del beneficio o de un retorno económico positivo, y cambiándolo por la búsqueda de un servicio que atiende las necesidades de acceso al crédito y transferencias de riesgos financieros, priorizando los más necesitados.

Tabla 11 Finanzas éticas responsables

\begin{tabular}{lll}
\hline \multicolumn{1}{c}{ Núcleo } & \multicolumn{1}{c}{ Valor } & \multicolumn{1}{c}{ Equilibrio } \\
\hline Mercado- & Utilidad- & Búsqueda de un \\
Estado & crecimiento & beneficio justo, \\
como base & Consumo- & priorizando \\
de la & Producción- & proyectos
\end{tabular}




\begin{tabular}{|c|c|c|}
\hline $\begin{array}{l}\text { eficiencia y } \\
\text { relaciones } \\
\text { económicas }\end{array}$ & $\begin{array}{l}\text { Inversión } \\
\text { más } \\
\text { sostenibles }\end{array}$ & $\begin{array}{l}\text { sociales y } \\
\text { ambientales }\end{array}$ \\
\hline $\begin{array}{l}\text { Sostenibili } \\
\text { dad }\end{array}$ & Sociedad & Responsabilidad \\
\hline $\begin{array}{l}\text { Alto } \\
\text { Sólo se } \\
\text { invierte en } \\
\text { proyectos } \\
\text { respetuosos } \\
\text { medioambi } \\
\text { ente y } \\
\text { proyectos } \\
\text { sociales }\end{array}$ & $\begin{array}{l}\text { Medio } \\
\text { Prioridad } \\
\text { por } \\
\text { proyectos } \\
\text { sociales y } \\
\text { acceso } \\
\text { crédito a } \\
\text { desfavorecid } \\
\text { os, aunque } \\
\text { con precios } \\
\text { de mercado }\end{array}$ & $\begin{array}{l}\text { Medio } \\
\text { Impacto indirecto } \\
\text { por la política de } \\
\text { inversión }\end{array}$ \\
\hline
\end{tabular}

Fuente: elaboración propia

\section{2) Economía evolutiva (Eev)}

Tabla 12 Economía evolutiva

\begin{tabular}{|c|c|c|}
\hline Núcleo & Valor & Equilibrio \\
\hline $\begin{array}{l}\text { Mercado- } \\
\text { Estado } \\
\text { como } \\
\text { mecanismo } \\
\text { dinámico } \\
\text { de } \\
\text { eficiencia y } \\
\text { regulación }\end{array}$ & $\begin{array}{l}\text { Utilidad- } \\
\text { crecimiento } \\
\text { limitado } \\
\text { por } \\
\text { dinámica } \\
\text { Consumo- } \\
\text { producción }\end{array}$ & $\begin{array}{l}\text { Trayectoria } \\
\text { evolutiva } \\
\text { gobernada desde } \\
\text { una decisión } \\
\text { racional limitada }\end{array}$ \\
\hline $\begin{array}{l}\text { Sostenibili } \\
\text { dad }\end{array}$ & Sociedad & $\begin{array}{l}\text { Responsabilida } \\
\text { d }\end{array}$ \\
\hline $\begin{array}{l}\text { Alto } \\
\text { Base } \\
\text { biológica y } \\
\text { holística de } \\
\text { la } \\
\text { interrelació } \\
\text { n } \\
\text { económica }\end{array}$ & $\begin{array}{l}\text { Bajo } \\
\text { Prioridad } \\
\text { medio } \\
\text { natural }\end{array}$ & $\begin{array}{l}\text { Medio } \\
\text { Efectos } \\
\text { dinámicos pero } \\
\text { sin penalizar la } \\
\text { decisión }\end{array}$ \\
\hline
\end{tabular}

\section{3) Economía del decrecimiento (Edc)}

Tabla 13 Economía del decrecimiento

\begin{tabular}{lll}
\hline \multicolumn{1}{c}{ Núcleo } & \multicolumn{1}{c}{ Valor } & \multicolumn{1}{c}{ Equilibrio } \\
\hline Estado como & Utilidad- & Estado estacionario \\
mecanismo & crecimient & de riqueza y \\
o limitado & población acorde \\
las & Consumo- & capacidad \\
posibilidades & producció & planetaria e \\
crecimiento & n limitados & igualdad entre \\
económico & & colectivos y zonas
\end{tabular}

\begin{tabular}{lll}
\hline Sostenibilidad & Sociedad & Responsabilidad \\
\hline Muy alto & Alto & Medio \\
Limitación & Principal & Limitación \\
crecimiento & mente por & posibilidades de \\
& imposició & crecimiento por \\
& $\mathrm{n}$ & imposición \\
& igualdad & \\
& & \\
\end{tabular}

Fuente: elaboración propia

\section{4) Economía sostenible (Eso)}

Tabla 14 Economía sostenible

\begin{tabular}{|c|c|c|}
\hline Núcleo & Valor & Equilibrio \\
\hline $\begin{array}{l}\text { Mercado- } \\
\text { Estado } \\
\text { como } \\
\text { mecanismo } \\
\text { eficiente y } \\
\text { regulatorio } \\
\text { de oferta- } \\
\text { demanda, } \\
\text { pero } \\
\text { limitado al } \\
\text { crecimiento } \\
\text { que no } \\
\text { afecte } \\
\text { posibilidade } \\
\text { s futuras }\end{array}$ & $\begin{array}{l}\text { Utilidad- } \\
\text { crecimiento } \\
\text { limitado } \\
\text { Consumo- } \\
\text { producción } \\
\text { limitados }\end{array}$ & $\begin{array}{l}\text { Estado } \\
\text { estacionario de } \\
\text { riqueza y } \\
\text { población acorde } \\
\text { capacidad } \\
\text { planetaria }\end{array}$ \\
\hline $\begin{array}{l}\text { Sostenibilid } \\
\text { ad }\end{array}$ & Sociedad & Responsabilidad \\
\hline $\begin{array}{l}\text { Muy alto } \\
\text { Limitación } \\
\text { crecimiento }\end{array}$ & $\begin{array}{l}\text { Medio } \\
\text { Prioridad } \\
\text { derechos } \\
\text { futuros. } \\
\text { Presentes } \\
\text { limitados a } \\
\text { posibilidades } \\
\text { crecimiento }\end{array}$ & $\begin{array}{l}\text { Alto } \\
\text { Limitación } \\
\text { posibilidades que } \\
\text { afecten al futuro }\end{array}$ \\
\hline
\end{tabular}

\section{5) Economía esférica (Ees)}

Tabla 15 Economía esférica

\begin{tabular}{|c|c|c|}
\hline Núcleo & Valor & Equilibrio \\
\hline $\begin{array}{l}\text { Mercado- } \\
\text { Estado } \\
\text { como base } \\
\text { de la } \\
\text { eficiencia y } \\
\text { relaciones } \\
\text { económicas }\end{array}$ & $\begin{array}{l}\text { Utilidad- } \\
\text { crecimiento } \\
\text { Consumo- } \\
\text { Producción } \\
\text { circulares y } \\
\text { sociales }\end{array}$ & $\begin{array}{l}\text { Reaprovechamiento } \\
\text { de todo subproducto } \\
\text { con valor social }\end{array}$ \\
\hline Sostenibilid & Sociedad & Responsabilidad \\
\hline
\end{tabular}




\begin{tabular}{lll}
\hline ad & & \\
\hline Muy alto & Alto & Alto \\
Énfasis en la & Incorporaci & Impacto derivado de \\
producción & ón del valor & la circularidad y \\
circular & social en la & valor social \\
& diversificac & \\
& ión & \\
& innovacione & \\
& s & \\
& & \\
\hline
\end{tabular}

Fuente: elaboración propia

16) Economía ecológica (Eec)

Tabla 16 Economía ecológica

\begin{tabular}{|c|c|c|}
\hline Núcleo & Valor & Equilibrio \\
\hline $\begin{array}{l}\text { Interrelación } \\
\text { medio } \\
\text { natural- } \\
\text { producción } \\
\text { económica } \\
\text { como } \\
\text { mecanismo } \\
\text { regulatorio } \\
\text { de oferta- } \\
\text { demanda }\end{array}$ & $\begin{array}{l}\text { Utilidad- } \\
\text { biomasa/e } \\
\text { nergía }\end{array}$ & $\begin{array}{l}\text { Capacidad } \\
\text { reproductiva natural } \\
\text { - riqueza } \\
\text { estacionaria en largo } \\
\text { plazo (capacidad } \\
\text { planetaria de } \\
\text { producción- } \\
\text { consumo) }\end{array}$ \\
\hline
\end{tabular}

\begin{tabular}{lll}
\hline $\begin{array}{l}\text { Sostenibilid } \\
\text { ad }\end{array}$ & Sociedad & Responsabilidad \\
\hline Muy alto & Medio & Alto \\
Base de la & Prioridad & Efectos irreversibles \\
interrelación & medio & \\
económica & natural & \\
& & \\
\hline Fuente: elaboración propia &
\end{tabular}

\section{7) Economía circular (Eci)}

Tabla 17 Economía circular

\begin{tabular}{|c|c|c|}
\hline Núcleo & Valor & Equilibrio \\
\hline $\begin{array}{l}\text { Incentivo de la } \\
\text { circularidad y } \\
\text { aprovechamiento } \\
\text { en las relaciones } \\
\text { económicas y } \\
\text { productivas }\end{array}$ & $\begin{array}{l}\text { Utilidad- } \\
\text { crecimient } \\
\text { o sin } \\
\text { residuos } \\
\text { Producció } \\
\text { n- } \\
\text { Consumo- } \\
\text { producció } \\
\text { n sin } \\
\text { residuos }\end{array}$ & $\begin{array}{l}\text { El reciclaje y } \\
\text { reaprovechamiento } \\
\text { generalizado permite } \\
\text { pensar en ciclos } \\
\text { productivos } \\
\text { sostenibles que } \\
\text { cambien con la } \\
\text { tecnología }\end{array}$ \\
\hline Sostenibilidad & Sociedad & Responsabilidad \\
\hline $\begin{array}{l}\text { Muy alto } \\
\text { Reaprovechamien } \\
\text { to sin generación } \\
\text { de residuos }\end{array}$ & $\begin{array}{l}\text { Bajo } \\
\text { Sólo } \\
\text { enfoque } \\
\text { reciclaje }\end{array}$ & $\begin{array}{l}\text { Alto } \\
\text { El aprovechamiento } \\
\text { de los residuos limita } \\
\text { el impacto nocivo }\end{array}$ \\
\hline
\end{tabular}

Fuente: elaboración propia

\subsection{Enfoques de prioridad social}

Enfoques económicos donde la dimensión social tiene una importancia destacada:

\section{8) Economía marxista (Ema)}

Tabla 18 Economía marxista

\begin{tabular}{|c|c|c|}
\hline Núcleo & Valor & Equilibrio \\
\hline $\begin{array}{l}\text { Estado como } \\
\text { mecanismo } \\
\text { eficiente y de } \\
\text { regulación } \\
\text { Dinámica } \\
\text { subyacente: } \\
\text { lucha de } \\
\text { clases }\end{array}$ & $\begin{array}{l}\text { Trabajo- } \\
\text { producción }\end{array}$ & $\begin{array}{l}\text { Estado estacionario } \\
\text { con fin capitalismo } \\
\text { y regulación } \\
\text { estatal/socialismo }\end{array}$ \\
\hline $\begin{array}{l}\text { Sostenibilid } \\
\text { ad }\end{array}$ & Sociedad & Responsabilidad \\
\hline $\begin{array}{l}\text { Muy Bajo } \\
\text { Sólo cuando } \\
\text { los efectos } \\
\text { son } \\
\text { importantes }\end{array}$ & $\begin{array}{l}\text { Alto } \\
\text { Prioridad } \\
\text { clase } \\
\text { trabajadora }\end{array}$ & $\begin{array}{l}\text { Bajo } \\
\text { Sólo si } \\
\text { distorsionan el } \\
\text { mercado }\end{array}$ \\
\hline
\end{tabular}

Fuente: elaboración propia

19) Economía colaborativa (Eco)

Tabla 19 Economía colaborativa

\begin{tabular}{|c|c|c|}
\hline Núcleo & Valor & Equilibrio \\
\hline $\begin{array}{l}\text { Mercado- } \\
\text { Estado sin } \\
\text { necesidad } \\
\text { propiedad }\end{array}$ & $\begin{array}{l}\text { Utilidad- } \\
\text { crecimiento } \\
\text { sin } \\
\text { necesidad de } \\
\text { propiedad } \\
\text { Consumo- } \\
\text { Producción } \\
\text { compartidos }\end{array}$ & $\begin{array}{l}\text { La satisfacción de } \\
\text { las necesidades sin } \\
\text { requerir un } \\
\text { aumento marginal } \\
\text { de los costes } \\
\text { sociales }\end{array}$ \\
\hline $\begin{array}{l}\text { Sostenibilid } \\
\text { ad }\end{array}$ & Sociedad & Responsabilidad \\
\hline $\begin{array}{l}\text { Medio } \\
\text { Efecto } \\
\text { derivado de } \\
\text { compartir }\end{array}$ & $\begin{array}{l}\text { Alto } \\
\text { Efecto } \\
\text { derivado de } \\
\text { no } \\
\text { limitación } \\
\text { propiedad }\end{array}$ & $\begin{array}{l}\text { Medio } \\
\text { Efecto derivado de } \\
\text { compartir }\end{array}$ \\
\hline
\end{tabular}

20) Economía de la felicidad (Efl) 
Tabla 20 Economía de la felicidad

\begin{tabular}{|c|c|c|}
\hline Núcleo & Valor & Equilibrio \\
\hline $\begin{array}{l}\text { Mercado- } \\
\text { Estado } \\
\text { como base } \\
\text { de la } \\
\text { eficiencia y } \\
\text { relaciones } \\
\text { económicas, } \\
\text { aunque } \\
\text { limitadas a } \\
\text { la } \\
\text { satisfacción } \\
\text { personal }\end{array}$ & $\begin{array}{l}\text { Utilidad- } \\
\text { crecimient } \\
\text { o hasta la } \\
\text { satisfacció } \\
\text { n } \\
\text { Consumo- } \\
\text { Producció } \\
\text { n }\end{array}$ & $\begin{array}{l}\text { La satisfacción y } \\
\text { felicidad persona no } \\
\text { competitiva contra el } \\
\text { resto }\end{array}$ \\
\hline $\begin{array}{l}\text { Sostenibilid } \\
\text { ad }\end{array}$ & Sociedad & Responsabilidad \\
\hline $\begin{array}{l}\text { Medio } \\
\text { Impacto } \\
\text { relativo } \\
\text { mientras } \\
\text { mejore } \\
\text { felicidad }\end{array}$ & $\begin{array}{l}\text { Alto } \\
\text { Prioridad } \\
\text { por la } \\
\text { felicidad } \\
\text { y } \\
\text { satisfacci } \\
\text { ón } \\
\text { personal }\end{array}$ & $\begin{array}{l}\text { Medio } \\
\text { Impacto relativo } \\
\text { mientras mejore } \\
\text { felicidad }\end{array}$ \\
\hline
\end{tabular}

Fuente: elaboración propia

\section{1) Economía feminista (Efm)}

Tabla 26 Economía feminista

\begin{tabular}{|c|c|c|}
\hline Núcleo & Valor & Equilibrio \\
\hline $\begin{array}{l}\text { Mercado- } \\
\text { Estado como } \\
\text { base de la } \\
\text { eficiencia y } \\
\text { relaciones } \\
\text { económicas, } \\
\text { ampliado con } \\
\text { los costes y } \\
\text { tiempo } \\
\text { dedicado de } \\
\text { cuidados y } \\
\text { relaciones } \\
\text { sociales }\end{array}$ & $\begin{array}{l}\text { Utilidad- } \\
\text { crecimient } \\
\text { o } \\
\text { Consumo- } \\
\text { Producció } \\
\text { n ampliado } \\
\text { con costes } \\
\text { de } \\
\text { dedicación } \\
\text { no } \\
\text { remunerad } \\
\text { os }\end{array}$ & $\begin{array}{l}\text { El mismo del } \\
\text { mercado, pero con } \\
\text { costes añadidos }\end{array}$ \\
\hline Sostenibilidad & Sociedad & Responsabilidad \\
\hline $\begin{array}{l}\text { Bajo } \\
\text { Énfasis en la } \\
\text { parte social } \\
\text { invisibilizada }\end{array}$ & $\begin{array}{l}\text { Alto } \\
\text { Prioridad } \\
\text { por } \\
\text { trabajos } \\
\text { invisibiliz } \\
\text { ados no } \\
\text { remunera } \\
\text { dos }\end{array}$ & $\begin{array}{l}\text { Bajo } \\
\text { Impacto en la base } \\
\text { de las generaciones } \\
\text { futuras }\end{array}$ \\
\hline
\end{tabular}

Fuente: elaboración propia

\section{2) Economía del bien común-práctica (Ebc2)}

La economía del bien común (Ebc) parte de la dignidad humana, la solidaridad y la justicia, la sostenibilidad medioambiental y la transparencia y participación democrática para primar la colaboración y el beneficio mutuo o común, que son las dimensiones en las que se mide la riqueza y crecimiento, y las que darían acceso a los bienes y servicios, y no el dinero. Pero también se define o defiende una versión alternativa de la Ebc compatible con el sistema económico actual (Ebc2), que plantea añadir una serie de incentivos de premios y penalizaciones económicas y legales para que el beneficio empresarial se ajuste según el valor del índice del producto o balance del bien común, de forma que a mayor índice mayor beneficio.

Tabla 22 Economía del bien común práctica

\begin{tabular}{|c|c|c|}
\hline Núcleo & Valor & Equilibrio \\
\hline $\begin{array}{l}\text { Mercado- } \\
\text { Estado } \\
\text { como base } \\
\text { de la } \\
\text { eficiencia } \\
\text { pero con } \\
\text { incentivos y } \\
\text { penalizacio } \\
\text { nes } \\
\text { económica } \\
\text { y legales }\end{array}$ & $\begin{array}{l}\text { Índice bien } \\
\text { común- } \\
\text { utilidad- } \\
\text { crecimiento } \\
\text { Índice bien } \\
\text { común- } \\
\text { beneficio- } \\
\text { consumo }\end{array}$ & $\begin{array}{l}\text { Las limitaciones } \\
\text { en la } \\
\text { sostenibilidad y } \\
\text { la justicia }\end{array}$ \\
\hline
\end{tabular}

\begin{tabular}{lll}
\hline $\begin{array}{l}\text { Sostenibili } \\
\text { dad }\end{array}$ & Sociedad & $\begin{array}{l}\text { Responsabilida } \\
\text { d }\end{array}$ \\
\hline Medio & Alto & Medio \\
Según & Según & Según \\
efectividad & efectividad & efectividad \\
penalizacio & penalizaci & penalizaciones e \\
nes e & ones e & incentivos \\
incentivos & incentivos & \\
& & \\
\hline Fuente: elaboración propia &
\end{tabular}

23) Economía de género (Ege)

Tabla 23 Economía de género

\begin{tabular}{lll}
\multicolumn{1}{c}{ Núcleo } & \multicolumn{1}{c}{ Valor } & \multicolumn{1}{c}{ Equilibrio } \\
\hline Mercado- & Utilidad- & El mismo del \\
Estado & crecimiento & mercado, pero con
\end{tabular}




\begin{tabular}{|c|c|c|}
\hline $\begin{array}{l}\text { como base } \\
\text { de la } \\
\text { eficiencia y } \\
\text { relaciones } \\
\text { económicas, } \\
\text { ampliado } \\
\text { con el } \\
\text { estudio } \\
\text { diferencia } \\
\text { de género }\end{array}$ & $\begin{array}{l}\text { igualitario } \\
\text { entre } \\
\text { géneros } \\
\text { Consumo- } \\
\text { Producción } \\
\text { equitativo } \\
\text { entre } \\
\text { géneros }\end{array}$ & $\begin{array}{l}\text { equidad e igualdad } \\
\text { de género }\end{array}$ \\
\hline $\begin{array}{l}\text { Sostenibilid } \\
\text { ad }\end{array}$ & Sociedad & Responsabilidad \\
\hline $\begin{array}{l}\text { Bajo } \\
\text { Énfasis en la } \\
\text { igualdad }\end{array}$ & $\begin{array}{l}\text { Alto } \\
\text { Prioridad } \\
\text { por } \\
\text { igualdad y } \\
\text { equidad de } \\
\text { género }\end{array}$ & $\begin{array}{l}\text { Medio } \\
\text { Impacto relativo en } \\
\text { la mejora de las } \\
\text { generaciones } \\
\text { futuras }\end{array}$ \\
\hline
\end{tabular}

Fuente: elaboración propia

\section{4) Economía crítica (Ecr)}

Tabla 30 Economía crítica

\begin{tabular}{|c|c|c|}
\hline Núcleo & Valor & Equilibrio \\
\hline $\begin{array}{l}\text { Mercado- } \\
\text { Estado- } \\
\text { Instituciones } \\
\text { como base } \\
\text { de la } \\
\text { eficiencia y } \\
\text { relaciones } \\
\text { económicas }\end{array}$ & $\begin{array}{l}\text { Utilidad- } \\
\text { crecimiento } \\
\text { social } \\
\text { Consumo- } \\
\text { Producción } \\
\text { equitativos }\end{array}$ & $\begin{array}{l}\text { Se cuestiona el } \\
\text { estado } \\
\text { estacionario } \\
\text { ideal, en el } \\
\text { sentido que } \\
\text { siempre hay } \\
\text { deficiencias }\end{array}$ \\
\hline $\begin{array}{l}\text { Sostenibilid } \\
\text { ad }\end{array}$ & Sociedad & Responsabilidad \\
\hline $\begin{array}{l}\text { Medio } \\
\text { Énfasis en la } \\
\text { crítica social } \\
\text { más que en } \\
\text { la } \\
\text { sostenibilida } \\
\text { d }\end{array}$ & $\begin{array}{l}\text { Alto } \\
\text { Crítica por } \\
\text { los efectos de } \\
\text { las crisis y } \\
\text { desfavorecid } \\
\text { os de los } \\
\text { modelos } \\
\text { económicos }\end{array}$ & $\begin{array}{l}\text { Bajo } \\
\text { Impacto indirecto }\end{array}$ \\
\hline
\end{tabular}

\section{5) Economía solidaria (Esd)}

Tabla 31 Economía solidaria

\begin{tabular}{lll}
\hline \multicolumn{1}{c}{ Núcleo } & \multicolumn{1}{c}{ Valor } & \multicolumn{1}{c}{ Equilibrio } \\
\hline Autoorganización & Necesidad & La atención de \\
y de las & - & las necesidades \\
instituciones & crecimient & es la que \\
& o & generaría las \\
& & relaciones
\end{tabular}

\begin{tabular}{lll} 
& $\begin{array}{l}\text { Consumo- } \\
\text { Producció } \\
\mathrm{n} \\
\text { autogestio } \\
\text { nados }\end{array}$ & $\begin{array}{l}\text { económicas } \\
\text { dentro de cada } \\
\text { grupo } \\
\text { autogestionado }\end{array}$ \\
\hline $\begin{array}{l}\text { Sostenibilidad } \\
\text { No impacto } \\
\text { nocivo }\end{array}$ & Sociedad & $\begin{array}{l}\text { Responsabilid } \\
\text { ad }\end{array}$ \\
& $\begin{array}{l}\text { Plto } \\
\text { por } \\
\text { atender al } \\
\text { grupo }\end{array}$ & $\begin{array}{l}\text { Bajo } \\
\text { Prioridad } \\
\text { presente }\end{array}$ \\
\hline Fuente: elaboración propia & \\
\hline
\end{tabular}

\section{6) Economía social (Esl)}

Tabla 32 Economía social

\begin{tabular}{lll}
\hline \multicolumn{1}{c}{ Núcleo } & \multicolumn{1}{c}{ Valor } & \multicolumn{1}{c}{ Equilibrio } \\
\hline Mercado- & Utilidad- & La equidad \\
Estado- & crecimient & añadida en el \\
Institucione & o social & equilibrio \\
s sociales & Consumo- & macroeconómico \\
como base & Producció & ortodoxo \\
de la & $\mathrm{n}$ & \\
eficiencia y & equitativos & \\
relaciones & & \\
económicas & & \\
\end{tabular}

\begin{tabular}{lll}
\hline $\begin{array}{l}\text { Sostenibilid } \\
\text { ad }\end{array}$ & Sociedad & $\begin{array}{l}\text { Responsabilida } \\
\text { d }\end{array}$ \\
\hline Medio & Muy alto & Medio \\
Énfasis en & Prioridad & Énfasis en la \\
la parte & por la & responsabilidad \\
social de la & equidad, & social \\
sostenibilida & la & \\
d & solidarida & \\
& d y la & \\
& protección & \\
& social & \\
& & \\
\hline Fuente: elaboración propia
\end{tabular}

\section{7) Economía del bien común (Ebc1)}

Tabla 27 Economía del bien común

\begin{tabular}{lll}
\hline \multicolumn{1}{c}{ Núcleo } & \multicolumn{1}{c}{ Valor } & \multicolumn{1}{c}{ Equilibrio } \\
\hline Estado- & Índice bien & Las limitaciones en \\
Empresas & común- & la sostenibilidad y \\
como base & utilidad- & la justicia \\
de la & crecimiento & \\
eficiencia y & Índice bien & \\
relaciones & común- & \\
económicas & &
\end{tabular}




\begin{tabular}{|c|c|c|}
\hline & $\begin{array}{l}\text { beneficio- } \\
\text { consumo }\end{array}$ & \\
\hline $\begin{array}{l}\text { Sostenibilid } \\
\text { ad }\end{array}$ & Sociedad & Responsabilidad \\
\hline Alto & Muy alto & Medio \\
\hline $\begin{array}{l}\text { Dimensión } \\
\text { de } \\
\text { valoración }\end{array}$ & $\begin{array}{l}\text { Prioridad } \\
\text { por la } \\
\text { dignidad } \\
\text { humana, } \\
\text { solidaridad } \\
\text { y justicia }\end{array}$ & $\begin{array}{l}\text { Componente } \\
\text { derivado del resto }\end{array}$ \\
\hline
\end{tabular}

Fuente: elaboración propia

\subsection{Enfoques económicos de prioridad la responsabilidad}

Enfoques económicos donde la dimensión de responsabilidad, desde una perspectiva moral, es visible en el sentido de preocupación por impedir o reparar el daño del funcionamiento económico:

\section{8) Economía institucional (Ein1)}

Tabla 28 Economía institucional (clásica)

\begin{tabular}{|c|c|c|}
\hline Núcleo & Valor & Equilibrio \\
\hline $\begin{array}{l}\text { Mercado- } \\
\text { Estado- } \\
\text { Institucione } \\
\text { s como } \\
\text { mecanismo } \\
\text { eficiente y } \\
\text { de } \\
\text { regulación: } \\
\text { supervisión } \\
\text { oferta- } \\
\text { demanda }\end{array}$ & $\begin{array}{l}\text { Utilidad- } \\
\text { competenc } \\
\text { ia } \\
\text { Consumo- } \\
\text { producción }\end{array}$ & $\begin{array}{l}\text { Largo plazo } \\
\text { estado } \\
\text { estacionario, } \\
\text { salvo tecnología } \\
\text { / innovación } \\
\text { (dinámica } \\
\text { empresarial) }\end{array}$ \\
\hline $\begin{array}{l}\text { Sostenibilid } \\
\text { ad }\end{array}$ & Sociedad & $\begin{array}{l}\text { Responsabilida } \\
\text { d }\end{array}$ \\
\hline Medio & Alto & Alto \\
\hline $\begin{array}{l}\text { Sin mucho } \\
\text { impacto }\end{array}$ & $\begin{array}{l}\text { Importanc } \\
\text { ia } \\
\text { institucion } \\
\text { es sociales } \\
\text { como } \\
\text { control }\end{array}$ & $\begin{array}{l}\text { Depende } \\
\text { funcionamiento } \\
\text { instituciones }\end{array}$ \\
\hline
\end{tabular}

29) Finanzas éticas justas (Fet2)

Tabla 29 Finanzas éticas justas

Núcleo $\quad$ Valor $\quad$ Equilibrio

\begin{tabular}{lll}
\hline Mercado- & Utilidad- & Acceso \\
Estado- & crecimiento & universal a \\
Instituciones & justo & los servicios \\
financieras & Consumo- & financieros \\
sociales como & Producción & lo que \\
base de la & -Inversión & mejora \\
eficiencia y & justos & elección \\
relaciones & & $\begin{array}{l}\text { intertemporal } \\
\text { económicas }\end{array}$ \\
\end{tabular}

\begin{tabular}{lll}
\hline Sostenibilidad & Sociedad & $\begin{array}{l}\text { Responsabili } \\
\text { dad }\end{array}$ \\
\hline Bajo & Alto & Alto \\
Poco impacto & Prioridad & Mejora \\
medioambienta & impacto & elección \\
1 & desfavorec & intertemporal \\
& idos y & de consumo \\
& necesitado & \\
& $\mathrm{s}$ & \\
\end{tabular}

Fuente: elaboración propia

30) Economía azul (Eaz1)

Tabla 30 Economía azul

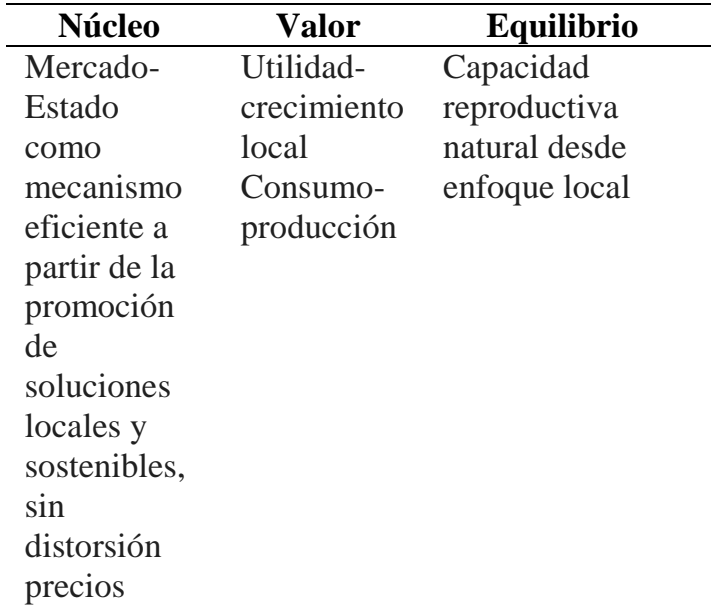

\begin{tabular}{lll}
\hline $\begin{array}{l}\text { Sostenibili } \\
\text { dad }\end{array}$ & Sociedad & $\begin{array}{l}\text { Responsabilida } \\
\text { d }\end{array}$ \\
\hline Alto & Bajo & Alto \\
Prioridad & Prioridad & $\begin{array}{l}\text { Centrada en la } \\
\text { respuesta local }\end{array}$ \\
innovacion & local & \\
es & & \\
respetuosas & & \\
\hline Fuente: elaboración propia &
\end{tabular}

31) Territorio socialmente sostenible y responsable (Tsr)

Tabla 31 Territorio socialmente sostenible y responsable 


\begin{tabular}{|c|c|c|}
\hline Núcleo & Valor & Equilibrio \\
\hline $\begin{array}{l}\text { Mercado- } \\
\text { Estado } \\
\text { como base } \\
\text { de la } \\
\text { eficiencia y } \\
\text { relaciones } \\
\text { económicas }\end{array}$ & $\begin{array}{l}\text { Utilidad- } \\
\text { crecimient } \\
\text { o local y } \\
\text { sostenible } \\
\text { Consumo- } \\
\text { Producció } \\
\text { n local }\end{array}$ & $\begin{array}{l}\text { Desarrollo local de } \\
\text { las zonas más } \\
\text { desfavorecidas }\end{array}$ \\
\hline $\begin{array}{l}\text { Sostenibilid } \\
\text { ad }\end{array}$ & Sociedad & Responsabilidad \\
\hline $\begin{array}{l}\text { Alto } \\
\text { Énfasis en el } \\
\text { impacto } \\
\text { ambiental }\end{array}$ & $\begin{array}{l}\text { Medio } \\
\text { Énfasis en } \\
\text { la mejora } \\
\text { local y de } \\
\text { las zonas } \\
\text { desfavore } \\
\text { cidas }\end{array}$ & $\begin{array}{l}\text { Alto } \\
\text { Impacto indirecto }\end{array}$ \\
\hline
\end{tabular}

Fuente: elaboración propia

32) Economía del donut (Edo)

Tabla 32 Economía del donut

\begin{tabular}{|c|c|c|}
\hline Núcleo & Valor & Equilibrio \\
\hline $\begin{array}{l}\text { Mercado- } \\
\text { Estado } \\
\text { autoregula } \\
\text { ndose } \\
\text { dentro de } \\
\text { las } \\
\text { posibilida } \\
\text { des y } \\
\text { recursos } \\
\text { del } \\
\text { planeta }\end{array}$ & $\begin{array}{l}\text { Utilidad- } \\
\text { crecimient } \\
\text { o limitado } \\
\text { Consumo- } \\
\text { Producción } \\
\text { limitados }\end{array}$ & $\begin{array}{l}\text { La capacidad } \\
\text { de recursos } \\
\text { del planeta }\end{array}$ \\
\hline $\begin{array}{l}\text { Sostenibil } \\
\text { idad }\end{array}$ & Sociedad & $\begin{array}{l}\text { Responsabili } \\
\text { dad }\end{array}$ \\
\hline $\begin{array}{l}\text { Muy alto } \\
\text { Límite del } \\
\text { sistema } \\
\text { económic } \\
\text { o }\end{array}$ & $\begin{array}{l}\text { Medio } \\
\text { Dimensio } \\
\text { nes a } \\
\text { satisfacer } \\
\text { dentro de } \\
\text { las } \\
\text { posibilida } \\
\text { des del } \\
\text { planeta }\end{array}$ & $\begin{array}{l}\text { Alto } \\
\text { Derivado del } \\
\text { respecto } \\
\text { recursos del } \\
\text { planeta }\end{array}$ \\
\hline
\end{tabular}

Fuente: elaboración propia

\section{RESULTADOS}

El análisis de los impactos en las tres dimensiones consideradas de los 32 enfoques enumerados se resume en la Tabla 33. En la Figura 1 se traslada todo este análisis a un mapa, donde los ejes de coordenadas reflejan el impacte en las dimensiones de sostenibilidad y social, y el tamaño de cada punto el impacto en la dimensión de responsabilidad.

Cada color corresponde a la dimensión característica del enfoque (amarillo económica; verde sostenible-medioambiental; azul social; rojo responsable-moral).

Se observa que, en general, los enfoques de prioridad económica sobre todo son bajos en sostenibilidad y consideraciones sociales, los enfoques sostenibles se mueven en casi todo el espectro del mapa, los sociales tienden a olvidar la dimensión medioambiental, mientras que los responsables también tienden a estar cerca del centro.

Un mapa que ayuda a entender y clasificar mejor las políticas o gestión pública de las diferentes economías en tanto que están basadas, justificadas o aprovechan la narrativa discursiva del enfoque económico o sus conceptos clave que toman como referencia, además de cómo se sitúan las prioridades ESG.

\section{CONCLUSIONES}

Se han analizado hasta 32 enfoques económicos según 3 dimensiones (sostenibilidad, sociedad y responsabilidad) clasificados en cuatro grandes grupos según si los enfoques primaban la parte económica, la medioambiental, la social o la moral.

El resultado ha sido un mapa que describe como cada grupo se sitúa en 1-2 cuadrantes, y mostrando que las dimensiones sostenibilidad (impacto medioambiental) y sociedad (impacto social) son las más importantes porque los diferentes enfoques se concentran según su prioridad. Una dualidad medioambiental-social que también está presente en las estrategias actuales de respuesta de recuperación de la reciente crisis pandémica del 2020-2021, después que en la anterior crisis 2008-2010 (subprime) la respuesta casi unánime fue seguir las recetas de los enfoques que primaban las variables económicas son duros ajustes. 


\section{REFERENCIAS}

Algar, R. (2007). Collaborative consumption. leisurereport.co.uk.

Barnard, C.I. (1938). The Functions of the Executive. Cambridge, MA: Harvard University Press.

Bastidas, O. \& Richer, M. (2001). "Economía social y economía solidaria: intento de definición". Cayapa. Revista Venezolana de Economía Social, vol. 1, núm. 1, mayo, 2001.

Boatright, J. (1999). Ethics in finance. Massachusetts. Blackwell Publishers Inc

Boulding, K.E. (1981). Evolutionary Economics. SAGE Publications. Michigan.

Brundtland, G.H. (1987). Informe Comisión Brundtland. https://web.archive.org/web/20111003074433/http://worldinbalance.net/intagreements/1987 -brundtland.php

Bruyn, S. (1977). The Social Economy. Wiley, New York.

Bustelo, P. (1998). Teorías contemporáneas del desarrollo económico. Síntesis. Madrid.

Coase, R. (1937). "The Nature of the Firm”. Economica, vol. 4 (16): 386-405.

Coase, R. H. (1960). The problem of social cost. Journal of Law and Economics, 3, 1-44.

Defourny, J. (1992), “Orígenes, contextos y funciones de un tercer gran sector”. Economía Social, entre Economía Capitalista y Economía Pública. CIRIEC- España, Valencia, pp. 17-39.

Easterlin, R.A. (2004). “The Economics of Happiness”. Dædalus 133 (2): 26-33.

European Commission (2012). Blue Growth - Final Report. https://webgate.ec.europa.eu/maritimeforum/sites/maritimeforum/files/Blue Growth Final Report 13082012.pdf

Federici, S. (2004). Calibán y la bruja. Mujeres, cuerpo y acumulación originaria. Traficantes de Sueños. Madrid.

Felber, C. (2008). Nuevos valores para la economía. Deuticke

Felber, C. (2010). Die Gemeinwohl-Ökonomie - Das Wirtschaftsmodell der Zukunft.

Goldin, C. (2006). “The Quiet Revolution That Transformed Women's Employment, Education, and Family". American Economic Review, Papers and Proceedings, 96, pp. 1-21.

Gomez, C. (2016). El colapso de los microcréditos en la cooperación al desarrollo. La Catarata. Madrid.

Hamilton, W.H. (1919). "The Institutional Approach to Economic Theory," American Economic Review, 9(1), Supplement, pp. 309-318.

Journal of Applied Corporate Finance (2016). Special Issue about "Sustainabitity and shareholder value", vol 28(2).

Jover Torregrosa, D. (2012). "Territorios socialmente responsables: el trabajo comunitario como estrategia de desarrollo local". Papeles de relaciones ecosociales y cambio global, vol. 119, 145-159.

Kahneman, D. \& Diener, E. (2003). Well-being: the foundations of hedonic psychology. Russell Sage Foundation.

Kalecki, M.(1954). Theory of Economic Dynamics: An essay on cyclical and long- run changes in capitalist economy. Allen \& Unwin.

Krugman, P. (1999). The return of depression economics. Allen Lane.

Latouche, S. (2009). La apuesta por el decrecimiento: ¿cómo salir del imaginario dominante? Icaria. Barcelona.

Laville, J.L. (dir.) (1994), L'économie solidaire. Une perspective internationale. Desclée de Brouwer, Paris.

Lévesque, B. \& Mendell, M. (1999). "L'économíe sociale au Québec: éléments théoriques et empiriques pour le débat et la recherche". Cahiers du CRISES (Collectif de recherches sur les innovations sociales dans les entreprises, les syndicats et l'économie sociale), no 9908 , UQAM, Montreal. 
Llewellyn, k. (1931). "Legal Tradition and Social Science Method", en Essays on Research in the Social Sciences, ed. Brookings Institution, 1931, 89 ss.

Mankiw, N.G. (1997) Principles of Economics. Fort Worth, TX: Dryden Press.

Molero, R. (2016). Corrientes heterodoxas de pensamiento económico. Fundamentos e interrelaciones. En García, F \& Ruíz, A. Hacía una economía más justa, pp. 65-87 (http://ecosfron.org/wp-content/uploads/HACIA-UNA-ECONOMIA-MAS-JUSTA3_3_2016.pdf).

Moreno, M.A. (2012). Blog salmón. https://www.elblogsalmon.com/conceptos-de-economia/que-esla-economia-evolutiva

Naredo, J.M. (2004. "La economía en evolución: invento y configuración de la economía en los siglos XVIII y XIX y sus consecuencias actuales". Manuscrits, número 22, Pensamiento económico en la época moderna, pp. 83-117.

Naredo, J.M. (1987). La economía en evolución. Historia y perspectivas de las categorías básicas del pensamiento económico. S. XXI. Madrid.

Negroponte, N. (1995). Being digital. Hodder \& Stoughton. Great Britain.

Nelson, R. \& Winter, S. (1982). An Evolutionary Theory of Economic Change. The Belknap Press.

Nurkse, R. (1953). Problemas de formación de capital en los países insuficientemente desarrollados. Fondo de Cultura Económica. México. 1963.

Oaxaca, R. (1973). "Male-Female Wage Differentials in Urban Labor Markets", International Economic Review, 14 (3), pp. 693-709.

Pauli, G. (1994). The Blue Economy: 200 Projects Implemented US\$ 4 Billion Invested 3 Million Jobs Created. Academic Foundation

Pearce, D.W. \& Turner, R.K. (1990). Economics of natural resources and the environment. The John's Hopkins University Press.

Pearce, D.W., Markandya, A. \& Barbier, E.B. (1989). Blueprint for a Green Economy

Pérez Orozco, A. (2005). “Economía del Género y Economía Feminista. ¿Conciliación o ruptura?”. Revista venezolana de estudios de la mujer, 10 (24), pp. 43-64.

Picchio, A. (2001). Un enfoque macroeconómico "ampliado" de las condiciones de vida. Mimeo.

Pigou, A.C. (1920). The Economics of Welfare.

Raworth, K. (2013). Doughnut Economics.

Robinson, J. (1954). "The Production Function and the Theory of Capital". The Review of Economic Studies, Vol. 21, No. 2. (1953 - 1954), pp. 81-106.

Rosenstein-Rodan, P. (1943): "Problemas de la industrialización de Europa Oriental y Sudoriental" en Agarwala, A.N. y Singh, S.P. (eds.) (1963): La economía del subdesarrollo. Tecnos. Madrid. 1963. pp. 207-215

Samuelson, P. (1943). Foundations of Economic Analysis. Harvard University Press.

Schumpeter, P. (1911). Theorie der wirtschaftlichen Entwicklung.

Stiglitz, J. (1993). "Post Walrasian and post Marxian economics". J. of Economic Perspectives 7, pp. 109-14.

Tapscott, D. (1995). The Digital Economy: Promise and Peril in the Age of Networked Intelligence. McGraw-Hill Education.

Veblen, T. (1909). “The Limitations of Marginal Utility”. History of Economic Thought Articles, 17, issue.

Veenhoven, R. (1991). “Is happiness relative?”. Social indicators research, vol. 24(1), pp. 1-34.

Walras, L. (1896). Études d'économie sociale. Théorie de la répartition de la richesse sociale.

World Bank. (2016). Blue economy development framework. http://pubdocs.worldbank.org/en/446441473349079068/AMCOECC-Blue-

EconomyDevelopment-Framework.pdf

WWF. (2015). Principles for a Sustainable blue economy. http://www.wwf.se/source.php/1605623/15_1471_blue_economy_6_pages_final.pdf 
Tabla 33 Impacto por dimensiones de cada enfoque económico

\begin{tabular}{|c|c|c|c|c|c|c|c|}
\hline ENFOQUE & DESCRIPCIÓN & $\begin{array}{l}\text { SOSTE } \\
\text { NIBILI } \\
\text { DAD }\end{array}$ & $\begin{array}{l}\text { SOC } \\
\text { IAL }\end{array}$ & $\begin{array}{l}\text { RESPO } \\
\text { NSABI } \\
\text { LIDAD }\end{array}$ & $\begin{array}{c}\text { SOSTE } \\
\text { NIBILI } \\
\text { DAD }\end{array}$ & $\begin{array}{l}\text { SOC } \\
\text { IAL }\end{array}$ & $\begin{array}{l}\text { RESPO } \\
\text { NSABI } \\
\text { LIDAD }\end{array}$ \\
\hline $\begin{array}{l}\text { Economía } \\
\text { ortodoxa o } \\
\text { dominante (Eor) }\end{array}$ & $\begin{array}{l}\text { Mercado y utilidad } \\
\text { (clásicos, neoclásicos } \\
\text { Mankiw 1997) }\end{array}$ & $\begin{array}{l}\text { muy } \\
\text { bajo }\end{array}$ & $\begin{array}{l}\text { muy } \\
\text { bajo }\end{array}$ & bajo & 5 & 5 & 25 \\
\hline $\begin{array}{l}\text { Economía } \\
\text { neokeynesiana } \\
(\text { Ene) }\end{array}$ & $\begin{array}{l}\text { Mercado-Estado, } \\
\text { empleo (Samuelson } \\
1983 \text { ) }\end{array}$ & $\begin{array}{l}\text { muy } \\
\text { bajo }\end{array}$ & bajo & bajo & 10 & 25 & 30 \\
\hline $\begin{array}{l}\text { Economía } \\
\text { postkeynesiana } \\
(\text { Epo) }\end{array}$ & $\begin{array}{l}\text { Mercado-Estado, } \\
\text { empleo y dinámica } \\
\text { (Robinson 1954) }\end{array}$ & bajo & bajo & medio & 25 & 30 & 60 \\
\hline $\begin{array}{l}\text { Economía del } \\
\text { desarrollo (Eds) }\end{array}$ & $\begin{array}{l}\text { Salida retraso } \\
\text { (Rosenstein-Rodan } \\
\text { 1943) }\end{array}$ & bajo & bajo & bajo & 35 & 30 & 35 \\
\hline $\begin{array}{l}\text { Nueva Economía } \\
\text { institucional } \\
\text { (Ein2) }\end{array}$ & $\begin{array}{l}\text { Agentes complejos } \\
\text { (Coase } 1937 \text { y Barnand } \\
\text { 1938) }\end{array}$ & bajo & bajo & alto & 25 & 25 & 65 \\
\hline $\begin{array}{l}\text { Economía digital } \\
\text { (Edi) }\end{array}$ & $\begin{array}{l}\text { Mercado digital } \\
\text { (Negroponte 1995) }\end{array}$ & bajo & bajo & muy bajo & 20 & 20 & 10 \\
\hline $\begin{array}{l}\text { Economía } \\
\text { marxista (Ema) }\end{array}$ & $\begin{array}{l}\text { Estado-capital Marx } \\
(1867)\end{array}$ & muy bajo & alto & bajo & 10 & 85 & 30 \\
\hline $\begin{array}{l}\text { Economía } \\
\text { colaborativa (Eco) }\end{array}$ & $\begin{array}{l}\text { canvio propiedad por el } \\
\text { uso (Algar 2007) }\end{array}$ & medio & alto & medio & 60 & 65 & 45 \\
\hline $\begin{array}{l}\text { Economía de la } \\
\text { felicidad (Efl) }\end{array}$ & $\begin{array}{l}\text { satisfacción consumo } \\
\text { (Vennhoven 1991) }\end{array}$ & medio & alto & medio & 45 & 65 & 50 \\
\hline $\begin{array}{l}\text { Economía } \\
\text { feminista (Efm) }\end{array}$ & $\begin{array}{l}\text { invisibilización trabajo } \\
\text { no remunerado (Picchio } \\
\text { 2001) }\end{array}$ & bajo & alto & medio & 30 & 65 & 60 \\
\hline $\begin{array}{l}\text { Economía del bien } \\
\text { común práctica } \\
(\text { Ebc2) }\end{array}$ & $\begin{array}{l}\text { balance/índice bien } \\
\text { común (Felber 2010) }\end{array}$ & medio & alto & medio & 55 & 70 & 60 \\
\hline $\begin{array}{l}\begin{array}{l}\text { Economía } \\
\text { génere (Ege) }\end{array} \\
\end{array}$ & $\begin{array}{ll}\text { Igualdad } & \text { género } \\
\text { (Goldin 2006) } & \end{array}$ & bajo & alto & medio & 25 & 75 & 45 \\
\hline $\begin{array}{l}\text { Economía crítica } \\
(\text { Ecr })\end{array}$ & $\begin{array}{l}\text { Diversificación } \\
\text { alternativas }\end{array}$ & medio & alto & bajo & 50 & 80 & 30 \\
\hline $\begin{array}{l}\text { Economía } \\
\text { solidaria (Esd) }\end{array}$ & $\begin{array}{ll}\text { Autogestión } & \text { local } \\
\text { (Laville 1994) } & \end{array}$ & medio & alto & medio & 55 & 80 & 50 \\
\hline $\begin{array}{l}\text { Economía social } \\
(\text { Esl) }\end{array}$ & $\begin{array}{l}\text { Mercado-Estado- } \\
\text { instituciones sociales } \\
\text { (Walras 1896) }\end{array}$ & medio & $\begin{array}{l}\text { muy } \\
\text { alto }\end{array}$ & bajo & 60 & 95 & 60 \\
\hline $\begin{array}{l}\text { Economía del bien } \\
\text { común (Ebc1) }\end{array}$ & $\begin{array}{ll}\text { dignidad } & \text { humana } \\
\text { (Felber 2008) } & \end{array}$ & alto & $\begin{array}{l}\text { muy } \\
\text { alto }\end{array}$ & medio & 85 & 95 & 60 \\
\hline $\begin{array}{l}\text { Economía } \\
\text { ambiental (Eam) }\end{array}$ & $\begin{array}{l}\text { externalidades (Pigou } \\
1920 \text { y Coase } 1960)\end{array}$ & medio & bajo & medio & 55 & 30 & 35 \\
\hline $\begin{array}{l}\text { Economía verde } \\
\text { (Eve) }\end{array}$ & $\begin{array}{l}\text { riesgos e incentivos } \\
\text { medioambientales } \\
\text { (Pearce, Markandya y } \\
\text { Barbier 1989) }\end{array}$ & medio & $\begin{array}{l}\text { medi } \\
\text { o }\end{array}$ & medio & 65 & 60 & 60 \\
\hline $\begin{array}{l}\text { Economía azul } \\
\text { marina (Eaz2) }\end{array}$ & $\begin{array}{l}\text { sostenibilidad recursos } \\
\text { marinos (UE-WWF) }\end{array}$ & medio & bajo & medio & 60 & 40 & 50 \\
\hline
\end{tabular}




\begin{tabular}{|c|c|c|c|c|c|c|c|}
\hline $\begin{array}{l}\text { Bioeconomía } \\
(\mathrm{Bec})\end{array}$ & $\begin{array}{l}\text { Crecimiento saludable, } \\
\text { descarbonización (UE) }\end{array}$ & alto & $\begin{array}{l}\text { medi } \\
\mathrm{o}\end{array}$ & bajo & 65 & 55 & 40 \\
\hline $\begin{array}{l}\text { Finanzas éticas } \\
\text { responsables } \\
(\text { Fet1) }\end{array}$ & 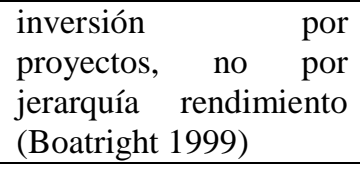 & alto & $\begin{array}{l}\text { medi } \\
\text { o }\end{array}$ & medio & 65 & 55 & 60 \\
\hline $\begin{array}{l}\text { Territorio } \\
\text { socialmente } \\
\text { sostenible y } \\
\text { responsable (Tsr) } \\
\end{array}$ & $\begin{array}{ll}\text { territorio } & \text { local } \\
\text { equilibrado } & \\
\end{array}$ & alto & $\begin{array}{l}\text { medi } \\
\text { o }\end{array}$ & alto & 70 & 60 & 70 \\
\hline $\begin{array}{l}\text { Economía } \\
\text { evolutiva (Eev) }\end{array}$ & $\begin{array}{l}\text { crecimiento limitado } \\
\text { interdisciplinarmente } \\
\text { (Nelson y Winter 1982) }\end{array}$ & alto & bajo & medio & 85 & 60 & 60 \\
\hline $\begin{array}{l}\text { Economía del } \\
\text { decrecimiento } \\
(\text { Edc })\end{array}$ & $\begin{array}{l}\text { Producción limitada } \\
\text { (Latouche 2009) }\end{array}$ & muy alto & alto & medio & 85 & 65 & 60 \\
\hline $\begin{array}{l}\text { Economía } \\
\text { sostenible (Eso) }\end{array}$ & $\begin{array}{ll}\text { Crecimiento } & \text { limitado } \\
\text { (Daly 1977) } & \\
\end{array}$ & muy alto & $\begin{array}{l}\text { medi } \\
\mathrm{o}\end{array}$ & alto & 90 & 60 & 80 \\
\hline $\begin{array}{l}\text { Economía esférica } \\
(\text { Ees })\end{array}$ & $\mathrm{ECi}+\mathrm{EBC}$ & muy alto & alto & alto & 90 & 65 & 70 \\
\hline $\begin{array}{l}\text { Economía } \\
\text { ecológica (Eec) }\end{array}$ & $\begin{array}{l}\text { Crecimiento biológico } \\
\text { (Georgescu-Roegen } \\
\text { 1971) }\end{array}$ & muy alto & $\begin{array}{l}\text { medi } \\
\text { o }\end{array}$ & alto & 95 & 45 & 80 \\
\hline $\begin{array}{l}\text { Economía circular } \\
(\text { Eci) }\end{array}$ & $\begin{array}{l}\text { Reaprovechamiento } \\
\text { (Pearce y Turner 1990) }\end{array}$ & muy alto & bajo & alto & 95 & 35 & 75 \\
\hline $\begin{array}{l}\text { Economía } \\
\text { institucional } \\
(\text { Ein1) } \\
\end{array}$ & $\begin{array}{l}\text { Mercado-Estado- } \\
\text { Instituciones (Veblen } \\
1909)\end{array}$ & medio & alto & alto & 65 & 85 & 65 \\
\hline $\begin{array}{l}\text { Finanzas éticas } \\
\text { justas (Fet2) }\end{array}$ & servicio financiero justo & bajo & alto & alto & 35 & 70 & 70 \\
\hline $\begin{array}{l}\text { Economía azul } \\
(\text { Eaz1) }\end{array}$ & $\begin{array}{l}\text { innovaciones } \\
\text { sostenibles } \\
\text { (Pauli 1994) }\end{array}$ & alto & bajo & alto & 75 & 35 & 75 \\
\hline $\begin{array}{l}\text { Economía } \\
\text { donut (Edo) }\end{array}$ & $\begin{array}{l}\text { limitación autoregulada } \\
\text { localmente } \quad \text { (Raworth } \\
\text { 2013) }\end{array}$ & muy alto & $\begin{array}{l}\text { medi } \\
\text { o }\end{array}$ & alto & 90 & 50 & 75 \\
\hline
\end{tabular}


Figura 1. Mapa de los enfoques económicos según las tres dimensiones de comparación

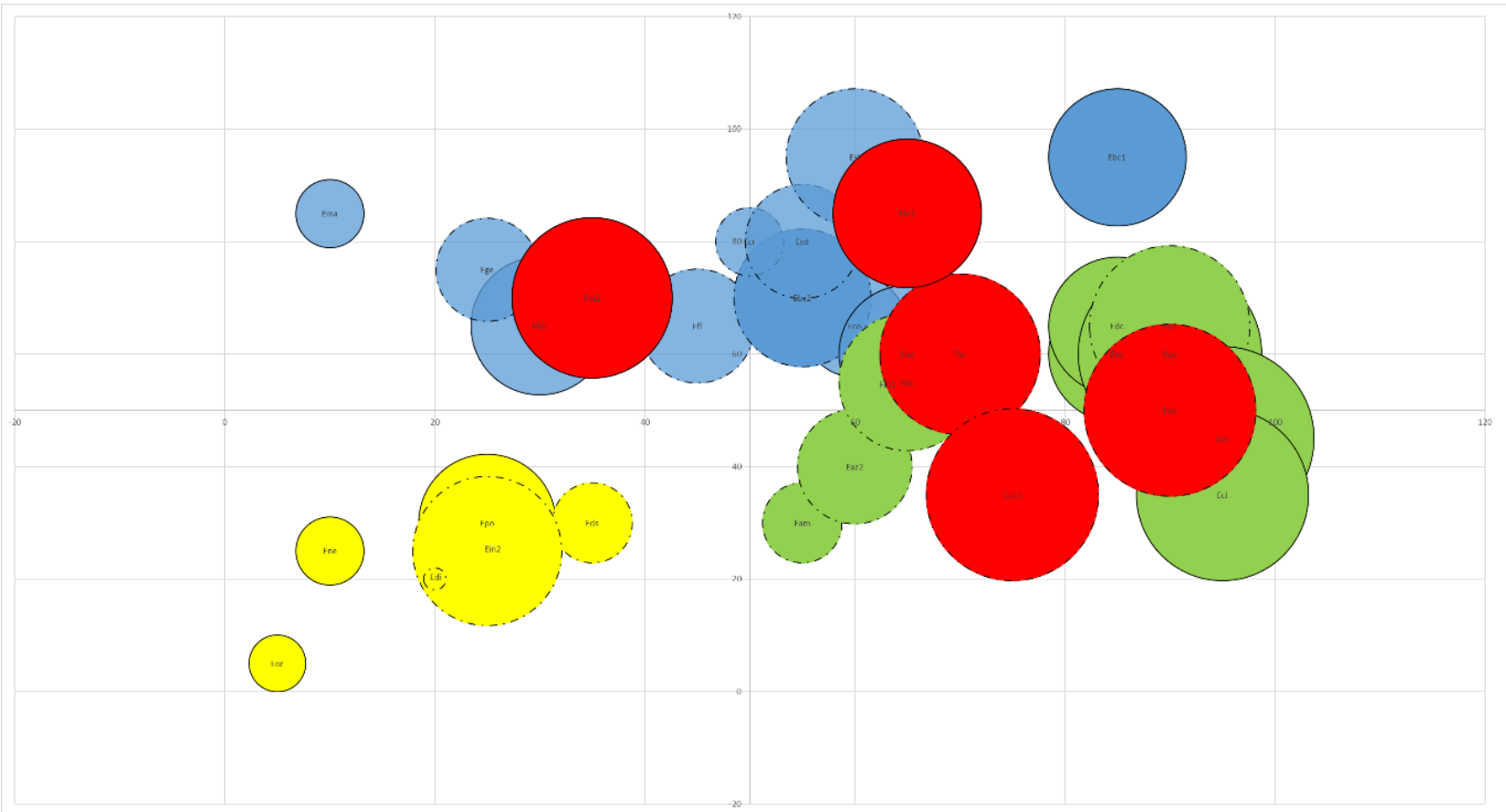

Fuente: Elaboración propia. 